\title{
Examining the Relationship between Academic Leaders' Communication Skills and their Social Media Usage
}

\author{
Dr. Abdulaziz Saeed Alqahtani \\ Associate professor, Educational Leadership, \\ King Khalid University, Saudi Arabia
}

\begin{abstract}
This study attempts to investigate the relationship between academic leaders' communication skills and their social media usage. To obtain data, the investigator ensured that surveys were sent to each of the four universities in the four geographical areas of Saudi Arabia. This survey instrument was randomly distributed to academic leaders of four universities in Saudi Arabia, and I received 848 surveys. The research showed that the overall average of leadership communication skills was 4.36, while the overall average of the use of social media was 4.30. The analysis of data reveals a statistically significant correlation between the level of academic leaders' communication skills and the level of their use of social media. The data shown above indicate that there was not a significant difference between social media usage in the workplace and leaders' communication skills regarding gender; social media platform; time on social media each day; workplace, personal, or business use; or positives and negatives of use.
\end{abstract}

Keywords: communication, social media, academic leaders.

\section{Introduction}

Usage of social media platforms at work can, in many situations, benefit productivity and the social life of the work environment (Nisar, Prabhakar \& Strakovaa, 2019). Social media is an active tool for marketing and advertising that is used as a platform to serve institutions, businesses, and people in many ways (Ganguly, 2015); gaining followers and posting news and pictures have effectively helped in the popularity and impact of businesses around the world. The advantages of social media for sharing information and connecting people have served the world both economically and socially. Social media, which was perceived as a tool for social connections with members of family, friends and acquaintances from different parts of the world is rapidly expanding to encompass the professional sphere of our lives in parallel with personal space (Gal, Jensen, \& Lyytinen, 2014; Jeppesen \& Fredricksen, 2006). 
Among the various professional fields, social media has influenced the field of education in a tremendous way and can potentially transform the learning environment significantly by eliminating the boundaries of the traditional classroom learning, providing more opportunities for collaboration between students and educators (Chen \& Bryer, 2012). The field of education is a very rich field when blended with technology, and the list of learning opportunities, tools, study groups, and online courses is growing rapidly. Facebook, Twitter, Pinterest, and LinkedIn are all social media platforms used in the education field, whether for promotional and marketing purposes or as learning tools. The capacity of knowledge expansion and what this trend can offer are limitless.

A significant number of people use social media platforms like Twitter, Instagram, LinkedIn or Facebook which help them to share different ideas, content, and information that significantly impact education (Kathuria, 2017). Social media is also very important for students, in that, it helps keep them stay connected with academics aiding in information interchange. Academicians too are dependent upon social media platforms for hosting lectures, branding themselves and for giving appropriate feedback to their students.

Powers and Green (2018) report the findings of their study of school principals which elicits that principals use a variety of social media platforms for communicating with students, teachers and parents and showed support for using such platforms for classroom instruction. It is also evident that the use of social media has still not reached its true potential in transferring the $21^{\text {st }}$ century skills to learners. Hence, the principals believe that there is a need to intensify the usage of social media platforms for instructional purposes, although doing so needs determination since it is a complex process.

Bonzo and Parchoma (2010) investigated the inconsistency between the expectations of the students and the institutions of higher education regarding the usage of different social media platforms for instructional purposes. The quality of social media platforms and the workplace have an impact on many of the educational institutions including education, financial, governmental and commercial institutions. Unfortunately, institutions of higher education lag behind in adopting the powerful educational tool that various social media platforms can provide.

According to Yilmaz, social constructivist learning consists of the following five fundamental factors (Yilmaz, 2008, p. 167):

1. Learning necessitates the active participation of students and is not passive.

2. Prior experiences along with new experience reinforce the adaption of that knowledge.

3. Positive social interaction leads to individualized knowledge construction within the environment.

4. Negotiation is the key to the growth of shared meaning within a learning environment and results in common knowledge.

5. Learning happens in a sociocultural context. 
A large number of employees and college students make use of social media in a similar fashion - tweeting about a rescheduled class, an event registration, or the extension of an assignment are examples of methods of using social media in the field of education, but when the social and personal prospects of a social media account are mixed with views and opinions that abstain from and evade matters and issues in the university community, the role of the social engine is shifted from positive to negative (Faizi, Afia, \& Chiheb, 2013). Leonardi and Treem (2012) believe that a large number of studies on the usage of social media platforms are not rooted in sound theoretical background since these are more platform-driven and ignore organizational and social dynamics.

Bose (2016) claims that social media platforms have changed the way in which modern business practices are carried out and have positively influenced the field of education as well. A large number of schools and institutions of higher education have begun using social media for promotional and marketing purposes in order to enhance their enrollments. A large majority of college students spend a significant amount of time on social media on daily basis. As a result, social media has shrunk the world and brought people closer than ever before. The beginning of this decade has witnessed a spurt in social media usage for socializing, advertising and marketing and has revolutionized communication like never before.

Research suggests that there are exceptional types of social media platforms that are used for learning purposes. These platforms provide a variety of features that can be easily incorporated for learning purposes. Based upon the needs, educators may choose to use blogs, online chat, video conferencing, website development, Wikis and several other features of these social media platforms (Darwish \& Lakhtaria, 2011).

\section{Purpose of the Study}

The purpose of this study was to investigate the relationship between academic leaders'communication skills and their use of social media.

\section{Research Questions}

1. How do academic leaders perceive their leadership communication skills?

2. How do academic leaders perceive their social media use?

3. What is the relationship between academic leaders' communication skills and their use of social media?

\section{Literature Review}

Using social media as a medium of communication between the members of a workplace is believed to help create a connected community. Joining employees in social media groups serves to connect the members of business on both the professional and social levels. Sharing social media accounts can help to introduce and reflect the interests and skills of group members, which creates a social bond and a connected environment. In a study conducted in 2018, Fusi and Feeney found a significant increase in relationships, 
customer service better communication among employees that regularly used social media platforms (Fusi \& Feeney, 2018).

Employees who make use of social media platforms to carry out their work tend to be more creative as a result of collaboration with friends, colleagues and other experts in their field (Bucholtz, 2018). Social media has enabled employees to stay in touch with current trends and digital tools. The use of new social media applications with new features influences the way employees approach tasks and tailor their own work to correspond to current trends. Employees bond with the community and are more willing to portray a positive impression of their workplace. With more than millions of users of Twitter and a billion members of Facebook (Smith, 2006), it has been proven that consumers are more likely to buy products that are advertised through social media. Likewise, with respect to world issues and campaigns, people are more involved with hashtags and Facebook likes and dislikes than TV ads and newspapers.

A primary concern regarding the usage of social media platforms at work is the invasion of employee privacy (Mcneal \& Schmedea, 2015). While social media may serve to connect people and create a bond between employees, the risk of privacy invasion is still an issue of employee fear. In many cases, employees use social media to post pictures of family vacations and friends and discuss issues that may interfere with the views and perceptions of their employers or organizations to which they belong, which could affect them professionally and personally. Although any information posted on the internet is regarded as public, employee's lives outside the workplace are regarded as private, and the lack of privacy and easy access is a threat to employees privacy, especially when using social media as a platform to discuss work and employers (Mcneal \& Schmedea, 2015). The risk of social media jeopardizing professional lives is not just limited to employees; students, and especially college students, are also at risk (Virginia University, 2016).

Wolniewicz, Tiamiyua, Weeks, \& Elhai (2018) claim that there are several negative effects on the usage of social media platforms. He calculates the productivity in accordance with value and time and suggests that increased value leads to a significant increase in productivity which does not hold true for the social media usage since the waste of time in using social media leads to decrease in value. There are workplaces involving heavy machinery and construction which prohibit the usage of social media due to safety concerns. As for students, several schools have policies that forbid students from using their phones in class, as the use of smartphones can, in many situations, act as a distraction that interferes with learning, since students, at times, use social media during class to post pictures and tag friends.

Social media is most popular among millennials and more than $25 \%$ of the time a college student is online is spent on social media platforms. By contrast, social media use among college students can also have a negative impact on their achievement, and multitasking in classrooms can distract students and affect their attention (Jacobsen \& Foste, 2011). 
On the social aspect, students who use social media websites are more comfortable in college than those that do not. . The support and relationships established through social networks help to support students through the experiences and hardships of college life and contributes to communities and social clubs' students choose to be part of (Kalpidou, Costin, \& Morris, 2011). The number of students using Facebook grows every year with thousands of students joining this platform every year. The use of social media among college students can, in many ways, benefit them academically; in situations in which students are hesitant and shy to participate in classrooms, they are more active and engaged in blog discussions and online study groups. In a study conducted in 2010, Junco and his fellow researchers found that the use of Twitter in learning activies resulted in better student engagement and student achievement (Junco et al., 2010). In virtual spaces such as these, students have the freedom to explore and be creative (Mulvihill \& Swaminathan, 2012).

Procrastinating is one of the major problems resulting from the social media platforms that people use. It has been found that due to the excessive usage of social media platforms, students tend to procrastinate and are more likely to complete and hand in their assignments late (Przepiorka, Błachnio, \& Díaz-Morales, 2016). Excessive use of social media also leads to lowering of academic achievement. In a recent study that was conducted by Ohio State University, it was found that students who used Facebook frequently spent less time on studies and achieved lower grades when compared to the students who used Facebook less frequently (Kalpidiou, Costin, \& Morris, 2011).

Although students emphasize the importance of offline relationships and the value of traditional communication, the benefits of interactive communication outweigh its risks; technology and social media networks are extraordinary tools that can be used productively in education if applied correctly (Talman, 2007).

\section{Data Collection}

To obtain data, the investigator ensured that surveys were sent to each of four universities (King Khalid University- Bisha University- Najran UniversityJazan University) in the four geographical areas of Saudi Arabia. The investigator asked academic leaders to review and complete the survey they received. For this to be accomplished:

1. The investigator received permission from Mind Tools content to use their survey.

2. The investigator had the universities mail out the surveys to each of the academic leaders, requesting that they fill out the surveys within one month and return them to me.

3. Once the completed surveys were received, the investigator analyzed and compiled the data to create a report of the findings from the data collected.

4. The investigator then reported recommendations. 


\section{Data Analysis}

The analysis of data was carried out by using descriptive as well as inferential statistical methods. To ensure that the findings are applicable to broader population and can be generalizable, a Chi-square test for goodness of fit was carried out. to determine the suitability of the findings for the broader population.

There were three main research questions for this study. For the first two research questions, we employed descriptive statistic to calculate the mean response which gave us the measure of central tendency and and also standard deviation to get the measure of dispersion. Additionally, the analysis provided frequencies and percentages in order to provide a general overview of the data from the respondents.

To address the third research question, a statistically significant correlation was found between the communication skills of the academic leader and the amount of their usage of the social media platforms.

\section{Sample}

This survey instrument was distributed at random to academic leaders of four universities in Saudi Arabia, and I received 848 surveys.

Table (1) Overall statistics of academic leaders who answered the survey

\begin{tabular}{|c|c|c|c|c|c|c|}
\hline & & Frequency & Percent & Chi & df & sig \\
\hline \multirow{2}{*}{ Gender } & Male & 483 & 57.0 & \multirow{2}{*}{16.420} & \multirow{2}{*}{1} & \multirow{2}{*}{0.001} \\
\hline & Female & 365 & 43.0 & & & \\
\hline \multirow{4}{*}{$\begin{array}{l}\text { From which social media } \\
\text { platform did you follow } \\
\text { the link? }\end{array}$} & Instagram & 21 & 2.5 & \multirow{5}{*}{1231.802} & \multirow{4}{*}{3} & \multirow{4}{*}{0.001} \\
\hline & Facebook & 82 & 9.7 & & & \\
\hline & Twitter & 93 & 11.0 & & & \\
\hline & WhatsApp & 652 & 76.9 & & & \\
\hline \multirow{4}{*}{$\begin{array}{l}\text { How often, on average, } \\
\text { do you spend on social } \\
\text { media each day? }\end{array}$} & less than 5 hours & 413 & 48.7 & & \multirow{4}{*}{3} & \multirow{4}{*}{0.001} \\
\hline & 5-10 hours & 166 & 19.6 & \multirow{3}{*}{309.575} & & \\
\hline & more than 10 hours & 209 & 24.6 & & & \\
\hline & $\begin{array}{l}\text { I don't use social } \\
\text { media. }\end{array}$ & 60 & 7.1 & & & \\
\hline \multirow{3}{*}{$\begin{array}{l}\text { How often, on average, } \\
\text { do you spend on social } \\
\text { media in the workplace? }\end{array}$} & 1-3 hours & 110 & 13.0 & \multirow{3}{*}{215.521} & \multirow{3}{*}{2} & \multirow{3}{*}{0.001} \\
\hline & more than 3 hours & 279 & 32.9 & & & \\
\hline & $\begin{array}{l}\text { I don t use social } \\
\text { media. }\end{array}$ & 459 & 54.1 & & & \\
\hline \multirow{6}{*}{$\begin{array}{l}\text { Is the time you spend on } \\
\text { social media for personal } \\
\text { or business use? } \\
\text { What do you think are } \\
\text { the positives and } \\
\text { negatives of social } \\
\text { media? }\end{array}$} & Personal & 810 & 95.5 & \multirow[b]{2}{*}{702.811} & \multirow[b]{2}{*}{1} & \multirow[b]{2}{*}{0.001} \\
\hline & Business & 38 & 4.5 & & & \\
\hline & positives & 545 & 64.3 & \multirow{3}{*}{387.781} & \multirow{3}{*}{2} & \multirow{3}{*}{0.001} \\
\hline & negatives & 208 & 24.5 & & & \\
\hline & neutral & 95 & 11.2 & & & \\
\hline & Total & 848 & 100.0 & & & \\
\hline
\end{tabular}

The table (1) illustrates the numbers in terms of gender; social media platform; time on social media each day; workplace, personal, or business use; and positives or negatives of use. There were 438 male academic leaders, representing $57 \%$ of the total amount. There were 652 academic leaders who 
followed WhatsApp, which was 76.9 percent of the total amount. There were 413 academic leaders who spent less than five hours on social media each day, which was 48.7 percent of the total amount. There were 459 academic leaders who did not use social media in the workplace, which was 54.1 percent of the total amount. There were 810 academic leaders who used social media for personal use, which was 95.5 percent of the total amount. There were 545 academic leaders who thought social media use was positive, which was 64.3 percent of the total amount.

There was not a significant difference between social media usage in the workplace and leaders' communication skills regarding gender; social media platform; time on social media each day; workplace, personal, or business use; or positives and negatives of use.

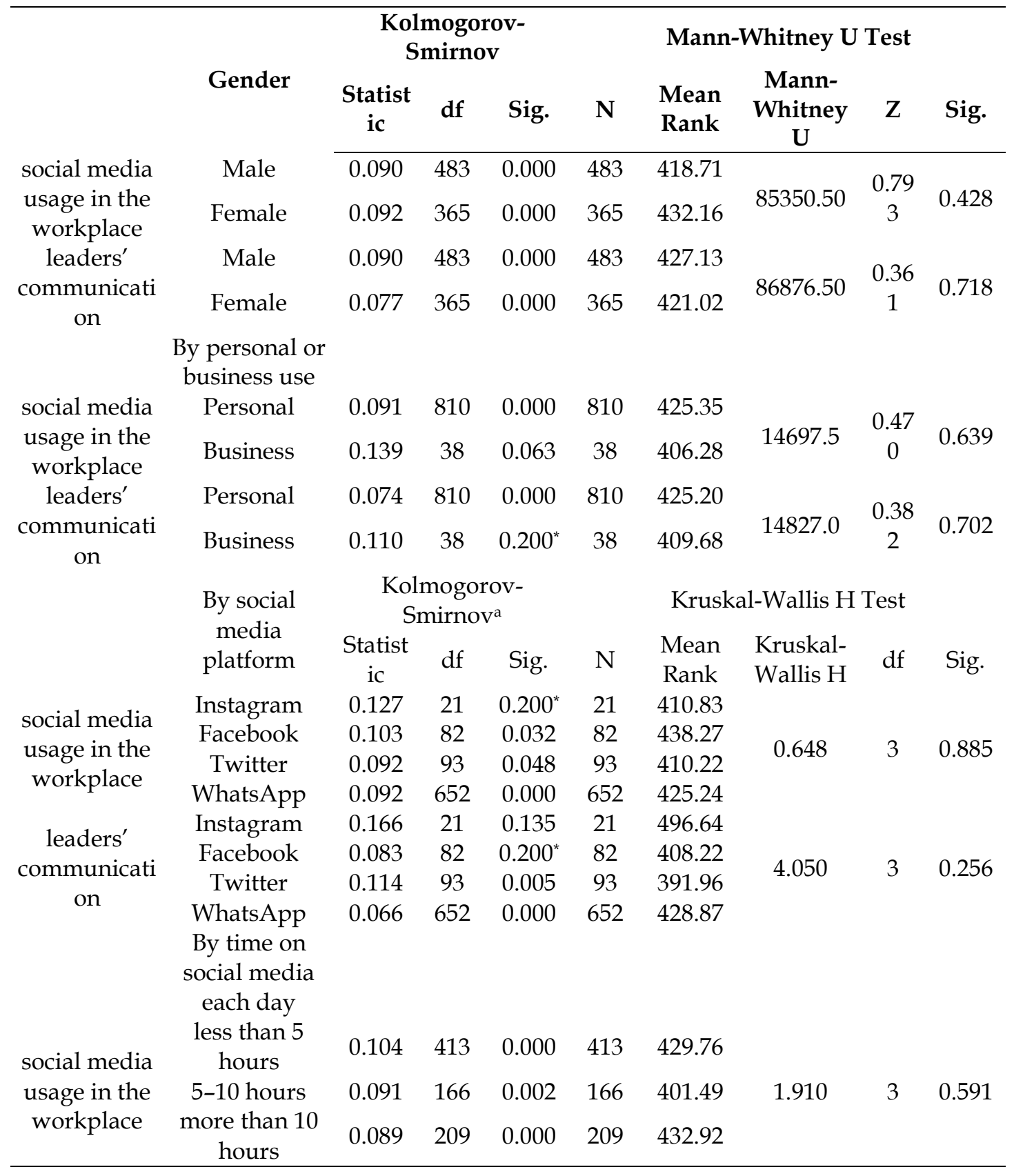




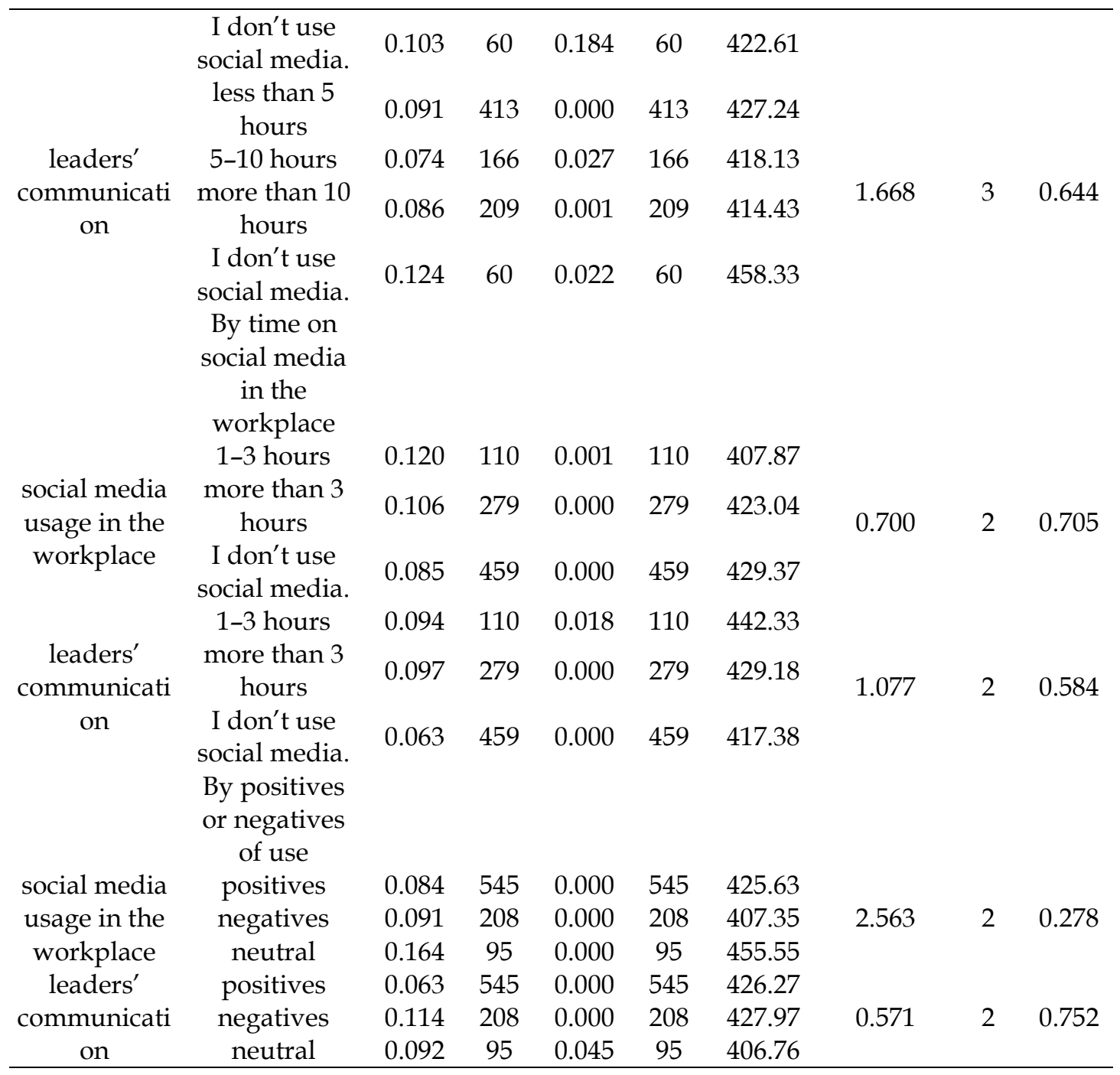

The data shown above indicate that there was not a significant difference between social media usage in the workplace and leaders' communication skills regarding gender; social media platform; time on social media each day; workplace, personal, or business use; or positives and negatives of use.

\section{Discussion and Finding}

Question 1: How do academic leaders identify their own leadership communication skills?

Based on the answers given in the completed surveys, the investigator found that academic leaders appeared to agree that they possessed leadership communication skills. The response to the questions related to the leadership communication skills reflected a score of 4.13 and higher. The scores reveal that the academic leaders believe in setting examples of the standard of excellence for others to emulate. The scores revealed that academic leaders could wean through the information quickly and identify relevant information and typos. 
Table (2) Average scores and ranking of academic leaders who answered the questions on their leadership communication skills

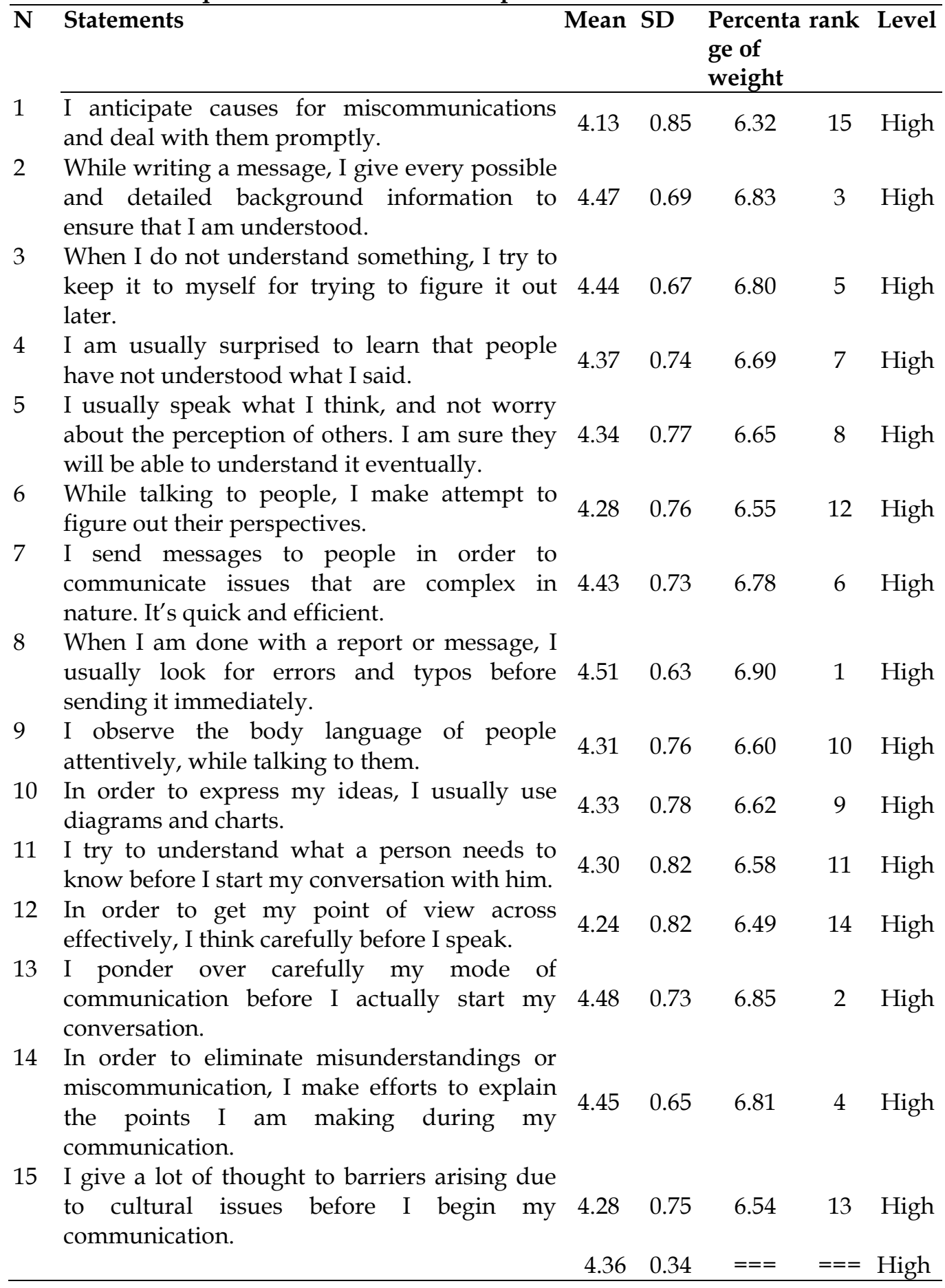

The overall average of "leadership communication skills" was 4.36. The highest average (4.51) was found in Question 8 about academic leaders' communication skills, which asked: "When I am done with a report or message, I usually look for errors and typos before sending it immediately". 


\section{Question 2: How do academic leaders perceive their social media use?}

The scores from the survey data, which was on an average 4.07 or higher, strongly indicated that academic leaders were unanimous in the usage of social media platforms for academic purposes. The academic leaders showed a strong inclination of openness and willingness to share information with others for mutual benefit.

Table (3) Average and ranking of academic leaders who answered the questions about using social media

\begin{tabular}{|c|c|c|c|c|c|c|}
\hline $\mathbf{N}$ & Statements: I use social media to: & Mean & SD & $\begin{array}{l}\text { Percen } \\
\text { tage of } \\
\text { weigh } \\
t\end{array}$ & & Level \\
\hline 1 & ... find the latest news about my job. & 4.07 & 0.75 & 5.57 & 17 & High \\
\hline 2 & $\begin{array}{l}\text {... connect and keep in touch with friends and } \\
\text { colleagues. }\end{array}$ & 4.15 & 0.81 & 5.68 & 16 & High \\
\hline 3 & ... open up and share information. & 4.49 & 0.68 & 6.14 & 1 & High \\
\hline 4 & ... promote research and innovation. & 4.22 & 0.78 & 5.78 & 14 & High \\
\hline 5 & ... engage in meetings. & 4.23 & 0.75 & 5.79 & 13 & High \\
\hline 6 & $\ldots$ as a crisis communications tool. & 4.43 & 0.70 & 6.06 & 2 & High \\
\hline 7 & ... participate online. & 4.31 & 0.73 & 5.90 & 8 & High \\
\hline 8 & ... follow people doing similar work. & 4.26 & 0.73 & 5.83 & 10 & High \\
\hline 9 & ... tell others about ongoing work or resources. & 4.42 & 0.65 & 6.05 & 3 & High \\
\hline 10 & ... self-promoter. & 4.25 & 0.75 & 5.81 & 11 & High \\
\hline 11 & ... give me ideas about content in a variety of fields. & 4.42 & 0.68 & 6.04 & 4 & High \\
\hline 12 & $\begin{array}{l}\text {... collaborate and brainstorm activities with } \\
\text { employees. }\end{array}$ & 4.35 & 0.71 & 5.94 & 7 & High \\
\hline 13 & ... raise issues and updates. & 4.24 & 0.75 & 5.80 & 12 & High \\
\hline 14 & ... know future plans. & 4.37 & 0.69 & 5.98 & 6 & High \\
\hline 15 & ... communicate with the external public & 4.22 & 0.77 & 5.77 & 15 & High \\
\hline 16 & ... discuss issues in the workplace. & 4.28 & 0.73 & 5.85 & 9 & High \\
\hline 17 & ... make a decision in the workplace. & $\begin{array}{l}4.40 \\
4.30\end{array}$ & $\begin{array}{l}0.68 \\
0.46\end{array}$ & $\begin{array}{l}6.02 \\
===\end{array}$ & $\begin{array}{l}5 \\
==\end{array}$ & $\begin{array}{l}\text { High } \\
\text { High }\end{array}$ \\
\hline
\end{tabular}

This data refers to leaders' perceptions of their usage of various social media platform which was 4.30 . The third question depicted a higher average of 4.49 .

\section{Question 3: Is there a relationship between academic leaders' communication skills and their use of social media?}

There is a statistically significant correlation between the level of academic leaders' communication skills and the level of their use of social media.

Table (4) Average score and rank of academic leaders answering questions about the relationship between academic leaders' communication skills and their social media usage.

\begin{tabular}{lcc}
\hline & Pearson Correlation & Sig. \\
\hline $\begin{array}{l}\text { social media usage in the workplace } \\
\text { leaders' communication skills }\end{array}$ & $0.510^{* *}$ & 0.01 \\
\hline
\end{tabular}

**. Correlation is significant at the 0.01 level. 
The results also showed a statistically significant correlation between the level of academic leaders' communication skills and the level of their use of social media. Only one item showed a negative statistically significant correlation between "connecting and keeping in touch with friends and colleagues" and "When I finish writing a report or message, I scan it quickly for typos and so forth and then send it off right away." The investigator expects that the leaders do not require editing or review when writing letters and reports to their friends and colleagues.

\begin{tabular}{lc}
\hline & $\begin{array}{r}\text { When I finish writing a report or message, I scan it quickly for typos } \\
\text { and so forth and then send it off right away. }\end{array}$ \\
$\begin{array}{c}\text { connect and keep in } \\
\text { touch with friends } \\
\text { and colleagues }\end{array}$ & $-0.069^{*}$ \\
\hline
\end{tabular}

\section{Conclusion}

The current study provides important insights into the usage of social media platforms by academic leaders and would be beneficial not only for the leaders themselves but institutions such as the Ministry of Education. The findings demonstrate how leaders identify the appropriate methods of communication in order to enhance the quality of their workplace. They use modeling and utilize personal examples directed at creating a standard of excellence for those around them to follow. Furthermore, they strive to paint a clear picture of the background information and details of the message.

This study provides better knowledge about the communication skills of academic leaders, which may also provide new insights for a more meaningful relationship between the Ministry of Education and the academic leaders. The academic leaders perceive themselves as the ones who motivate their people to look positively towards a brighter future and at the same time remain grounded in the process. The information gleaned from this investigation also helps others see what academic leaders think of their usage of various social media platforms for their day to day work.

\section{Acknowledgments}

I would like to convey my deep appreciation for the support and help provided by King Khalid University for this study.

\section{References}

Bose, A. (2016). Two Social Media and Education Sector: Enriching Two Relationship. Global Media Journal - Indian Edition. 7(1): 1-7

Bucholtz, L. (2018). Bridging bonds: Latvian migrants' interpersonal ties on social networking sites. Media, Culture and Society, 14(1), 104-119. doi:10.1177/0163443718764576

Chen, B., \& Bryer, T. (2012). Investigating instructional strategies for using social media in formal and informal learning. The International Review of Research in Open and Distributed Learning. 13(1): 87-104. 
Darwish, A., \& Lakhtaria, K. I. (2011). The Impact of the New Web 2.0 Technologies in Communication, Development, and Revolutions of Societies. Journal of Advances in Information Technology, 2(4): 204-216.

Fusi, F., \& Feeney, M. K. (2018). Social Media in the Workplace: Information Exchange, Productivity, or Waste? The American Review of Public Administration, 48(5), 395412. https://doi.org/10.1177/0275074016675722

Gal, U., Jensen, T., \& Lyytinen, K. (2014). Identity orientation, social exchange, and information technology use in interorganizational collaborations. Organization Science, 25 (5), 1372-1390

Ganguly, S. (2015). Why social media advertising is set to explode in the next 3 years. Marketing Land, March 17, https://marketingland.com/social-mediaadvertising-set-explode-next-3-years-121691

Jacobsen, W. \& Forste, R. (2011). The wired generation: Academic and social outcomes of electronic media use among university students. Cyber psychology, Behavior, and Social Networking, 14(5), 275-280.

Jeppesen, L. B., \& Fredricksen, L. (2006). Why do users contribute to firm-hosted user communities? The case of computer controlled music instruments, Organization Science, 17 (1), 45-63.

Junco, R., Heiberger, G. \& Loken, E. (2010) The effect of Twitter on college student engagement and grades. Journal of Computer Assisted Learning, 27 (2), 119132.

Kathuria, A. (2017). Importance of Social media in Higher Education. International Journal of Academic Research and Development, 2(4): 297-299

Leonardi, P. M., \& Treem, J. W. (2012). Knowledge management technology as a stage for strategic self-presentation: Implications for knowledge sharing in organizations. Information and Organization, 22(1), 37-59.

McNeal, R. S., \& Schmeida, M. (2015). Digital Paranoia: Unfriendly Social Media Climate Affecting Social Networking Activities. In J. Sahlin (Ed.), Social Media and the Transformation of Interaction in Society (pp. 210-227). Hershey, PA: IGI Global. doi:10.4018/978-1-4666-8556-7.ch011

Mulvihill, T. M., \& Swaminathan, R. (2012). Creativity And Learning In The Virtual Sphere: Perspectives From Doctoral Students. i-manager's Journal of Educational Technology, 9(3), 41-48. https://doi.org/10.26634/jet.9.3.2063

Nisar, T. M., Prabhakar, G., \& Strakovaa, L. (2019). Social media information benefits, knowledge management and smart organizations. Journal of Business Research, 94, 264-272. doi:10.1016/j.jbusres.2018.05.005

Powers, K \& Green, M. (2016). Principals' Perspectives on Social Media in Schools. The Journal of Social Media in Society, 5(2), 134- 168

Przepiorka, A., Błachnio, A., \& Díaz-Morales, J. F. (2016). Problematic Facebook use and procrastination. Computers in Human Behavior, 65:59-64. doi:10.1016/j.chb.2016.08.022

Faizi, R., Afia, A. E. and Chiheb, R. (2013). Exploring the Potential Benefits of Using Social Media in Education. International Journal of Engineering Pedagogy, 3(4): 5053, http://dx.doi.org/10.3991/ijep.v3i4.2836

Smith, W. (2006) Social marketing: an overview of approach and effects. Injury Prevention;12(Suppl I):i38-i43. doi: 10.1136/ip.2006.012864

Talman, D. (2007). Games With Limited Communication Structure. Center Discussion Paper Series No. 2007-19

Kalpidou, M., Costin, D., \& Morris, J. (2011). The Relationship Between Facebook and the Well-Beingof Undergraduate College Students. Cyberpsychology, Behavior and Social Networking. 14(4). doi:10.1089/cyber.2010.0061

Virginia University (2016). The University adopted the revised policy and procedures on an interim basis. http://www.virginia.edu/ 
Wolniewicz, C. A., Tiamiyua, M. F., Weeks J. W., \& Elhai, D. (2018). Problematic smartphone use and relations with negative affect, fear of missing out, and fear of negative and positive evaluation. Psychiatry Research, 262: 618-623. https://doi.org/10.1016/j.psychres.2017.09.058

Yilmaz, K. (2008) Constructivism: Its Theoretical Underpinnings, Variations, And Implications for Classroom Instruction. Educational Horizons, 86(3), 161-172. 